\title{
Discordant phenylketonuria phenotypes in one family: the relationship between genotype and clinical outcome is a function of multiple effects
}

LA Tyfield, J Zschocke, A Stephenson, F Cockburn, A Harvie, J L Bidwell, N A P Wood, L P Hunt

\begin{abstract}
Four members spanning three generations of one family have phenylketonuria of varying degrees of severity. Two first cousins were screened in the neonatal period and have had dietary phenylalanine restriction since diagnosis, the older patient having been classified as having more severe PKU and the younger one as having mild PKU. Their mutual grandfather and his older brother also have a significant hyperphenylalaninaemia and are of normal intelligence despite never having had restricted phenylalanine intake. Mutation analysis of the phenylalanine hydroxylase (PAH) gene has established that there are four different mutations, two in exon 2 (F39L and L48S) and two in exon 3 (R111X and $S 67 P$ ), which give rise to PKU in this family. In order to establish their relative severity, we screened the $P K U$ populations of western Scotland and the south west of England for these mutations. The exon 3 mutations are rare; however, F39L is relatively common in Scotland and $L 48 S$ in England. A comparison of diagnostic blood phenylalanine concentrations in subjects carrying L48S/null or F39L/null mutations with those carrying two null mutations suggest that these exon 2 mutations are less deleterious. Thus, in this family, the different biochemical phenotypes can be explained, in part, by different genotypes at the PAH locus but our results show that the relationship between genotype and clinical outcome is more complex and is a function of multiple effects.
\end{abstract}

( $(\mathcal{H}$ Med Genet 1995;32:867-870)

Department of Child for Sick Children, Yorkhill, Glasgow, UK F Cockburn

A Harvie

Department of Transplantation Sciences, University of Bristol, Bristol, UK J L Bidwell

N A P Wood

Institute of Child Health, University of Bristol, Bristol, UK L A Tyfield

L P Hunt

Correspondence to: Dr Tyfield.

Received 26 April 1995 Revised version accepted for publication 23 June 1995
Hyperphenylalaninaemia is usually caused by mutations at the phenylalanine hydroxylase (PAH) gene. To the end of October 1994, 206 different mutations have been reported by the PAH Mutation Analysis Consortium. ${ }^{1}$ In vitro expression analysis has shown that some result in a complete loss of enzyme activity whereas others are associated with residual activity ranging anywhere from 3 to $75 \% .^{2-6}$ It would be anticipated that various combinations of mutations would result in a full spectrum of biochemical phenotypes ranging from "classical" phenylketonuria (PKU) requiring strict dietary management to mild non-PKU hyperphenylalaninaemia in which dietary restriction of phenylalanine is not necessary.

In general, there appears to be a correlation between genotype and biochemical phenotype as determined by phenylalanine load studies or blood phenylalanine concentrations at diagnosis. ${ }^{4}$ However, large variation in intellectual outcome of untreated subjects with the same genotype has been observed both within and between families ${ }^{7}$ and this suggests that the relationship between genotype and clinical effect is probably more complex.

We previously reported a family in which there are four affected members spanning three generations. ${ }^{8}$ This included two first cousins who had different biochemical presentations in the neonatal period and their mutual grandfather and his older brother who had previously undiagnosed significant hyperphenylalaninaemia but were of apparently normal intelligence. Haplotype analysis made it likely that there were three, or possibly four, different mutations giving rise to PKU in the family.

In this paper we report the existence of four mutations at the PAH locus in this family, two in exon 2 (F39L and L48S) and two in exon 3 (R111X and S67P). We have established the relative frequency of these mutations in the PKU populations of south west England and western Scotland. In addition, diagnostic blood phenylalanine concentrations in subjects carrying L48S or F39L suggest that they are of a less deleterious type. S67P is a private mutation and also almost certainly associated with residual enzyme activity in vivo. Finally, although the different biochemical presentations of the affected subjects in this family can be explained, in part, by different genotypes, we believe that the clinical outcome of the untreated subjects provides additional evidence that there is not necessarily a simple correlation between phenotype and genotype at the PAH gene. 

III

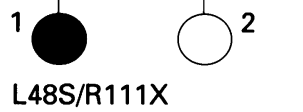

1
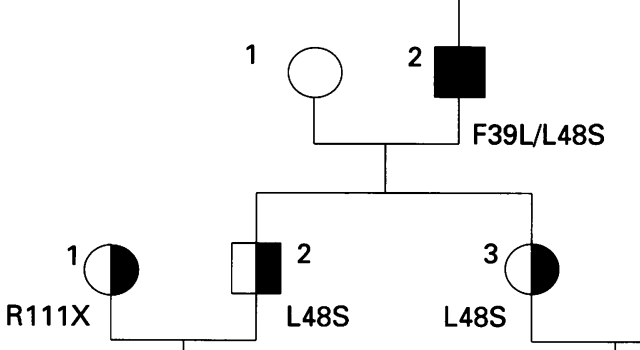

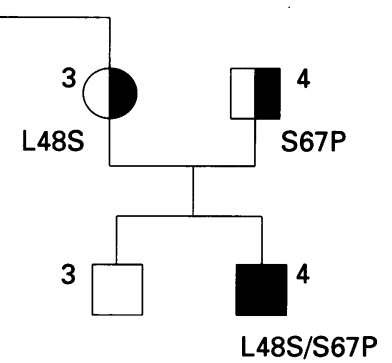

L48S/S67P

Figure $1 A$ concise family pedigree and the mutations that family members carried. Altogether there were five offspring in generation II. Only those with affected children are included.

Direct sequencing of amplified products using the ABI 373a automatic sequencer, as described elsewhere, ${ }^{12}$ or using a Cycle Sequencing kit (Pharmacia) was undertaken on those exons which showed banding patterns indicating the presence of an altered sequence.

Subsequently a synthetic construct was made to identify mutations in exon 2 , and a total of 308 independent alleles from the PKU populations of the south west of England and Scotland were screened for the four mutations that were identified in this family.

STATISTICAL METHODS

A comparison of blood phenylalanine concentrations at diagnosis was made for PKU subjects carrying F39L/null, L48S/null, and null/null mutations. Because there were regional differences in the relative frequencies of F39L and L48S (see Results), comparisons were made originally with subjects within the same population carrying two null mutations. A Kruskal-Wallis one way analysis of variance was used to see if there were differences among the four groups overall. Further comparisons between pairs of groups were made using two tailed Mann-Whitney U tests.

\section{Results}

Heteroduplex analysis showed that only III 4 had a banding pattern in exon 3 which suggested the presence of an altered sequence. Direct DNA sequencing established that this was a previously undescribed mutation, consisting of a $\mathrm{T}$ to $\mathrm{C}$ transition at codon 67 (TCT to $\mathrm{CCT}$ ), which substitutes a proline residue for serine in the PAH protein. Genetic analysis of the parents, II· 3 and II 4 , confirmed that this base change was inherited from II 4 and is associated with haplotype 4 . This mutation is also detectable by single stranded conformational polymorphism (SSCP) analysis (results not shown).

DGGE analysis established the presence of base changes in exons 2 and 3 in samples from I $\cdot 2$ and III $\cdot 1$. Direct sequencing of these exons showed them to be F39L (exon 2), L48S (exon 2), and R111X (exon 3). PCR amplification of these exons and restriction enzyme digestion with MaeIII, $M s c \mathrm{I}$, and $B s p \mathrm{HI}$ respectively showed that L48S was the mutation that all affected subjects had in common and was thus associated with haplotype 4 . R111X, inherited from II 1 , was associated with haplotype 5 and F39L with haplotype 1.

A compilation of various biochemical and

Table 1 Summary of genetic and biochemical parameters of key subjects in the pedigree

\begin{tabular}{|c|c|c|c|c|c|c|c|c|}
\hline & $I \cdot 2$ & $I \cdot 3$ & $I I \cdot 1$ & $I I \cdot 2$ & $I I \cdot 3$ & $I I \cdot 4$ & $I I I \cdot 1$ & $I I I \cdot 4$ \\
\hline $\begin{array}{l}\text { Blood phenylalanine at } \\
\text { diagnosis }(\mu \mathrm{mol} / 1)\end{array}$ & 1020 & 860 & - & - & - & - & 2500 & 650 \\
\hline $\begin{array}{l}\text { Age at diagnosis } \\
\text { Phenotype }\end{array}$ & $\begin{array}{l}63 \mathrm{y} \\
\text { Untreated PKU, } \\
\text { normal } \\
\text { intelligence }\end{array}$ & $\begin{array}{l}65 \mathrm{y} \\
\text { Untreated PKU, } \\
\text { normal } \\
\text { intelligence }\end{array}$ & $\overline{\text { Carrier }}$ & $\overline{\text { Carrier }}$ & $\overline{\text { Carrier }}$ & $\overline{\text { Carrier }}$ & $\begin{array}{l}7 \mathrm{~d} \\
\text { Treated PKU, } \\
\text { normal } \\
\text { intelligence }\end{array}$ & $\begin{array}{l}7 \mathrm{~d} \\
\text { Treated PKU, } \\
\text { normal } \\
\text { intelligence }\end{array}$ \\
\hline $\begin{array}{l}\text { PAH haplotypes } \\
\text { PAH genotype }\end{array}$ & $\begin{array}{l}1 / 4 \\
\text { F39L/L48S }\end{array}$ & $\begin{array}{l}1 / 4 \\
\text { F39L/L48S }\end{array}$ & $\begin{array}{l}5 / 5 \\
\text { R111X/ } \\
\text { normal }\end{array}$ & $\begin{array}{l}7 / 4 \\
\text { L48S/ } \\
\text { normal }\end{array}$ & $\begin{array}{l}4 / 4 \\
\text { L48S/ } \\
\text { normal }\end{array}$ & $\begin{array}{l}4 / 4 \\
\text { S67P/ } \\
\text { normal }\end{array}$ & $\begin{array}{l}4 / 5 \\
\mathrm{~L} 48 \mathrm{~S} / \mathrm{R} 111 \mathrm{X}\end{array}$ & $\begin{array}{l}4 / 4 \\
\mathrm{~L} 48 \mathrm{~S} / \mathrm{S} 67 \mathrm{P}\end{array}$ \\
\hline
\end{tabular}


Table 2 Relative frequencies and haplotype/VNTR associations of the four mutations in the PKU populations of south west England and western Scotland

\begin{tabular}{lllll}
\hline Place & $\begin{array}{l}\text { No of } \\
\text { alleles }\end{array}$ & Mutation & Rel frequency & $\begin{array}{l}\text { Haplotypel } \\
\text { VNTR }\end{array}$ \\
\hline SW England & 103 & F39L & $<1 \%$ & $1 \cdot 8$ \\
& & L48S & $7 \%$ & $4 \cdot 3$ \\
& & R111X & $<1 \%$ & $5 \cdot 8$ \\
S67P & $<1 \%$ & $4 \cdot 3$ \\
W Scotland & \multirow{2}{*}{206} & F39L & $6 \%$ & $? \cdot 8$ \\
& & L48S & $<1 \%$ & $? \cdot 3$ \\
& & R111X & 0 & \\
\hline
\end{tabular}

genetic parameters for key family members is given in table 1.

Two mutations, L48S and F39L, were found on additional PKU chromosomes in south west England and western Scotland. L48S was found more frequently in the south west of England whereas in Scotland it was F39L. Table 2 shows their relative frequencies and haplotype/VNTR associations in the two populations.

In order to ascertain the relative quantitative effects of these mutations on phenylalanine hydroxylase activity in vivo we compared blood phenylalanine concentrations at diagnosis in subjects whose genotypes were L48S/null or F39L/null with the values in subjects from the same population who carried two null mutations (fig 2). The null mutation in the English group was principally IVS12nt $1 \mathrm{~g} \rightarrow \mathrm{a}$ and in the Scottish group it was $\mathrm{R} 408 \mathrm{~W}$. There were significant differences among the four groups overall $(p=0.003)$. There was also a suggestion that the English and Scottish null/null groups were different but the difference did not achieve statistical significance $(p=0.053)$. Comparison between children with an L48S/null or F39L null genotype and children with both null mutations were therefore made separately for each country. In the Scottish series, the children with the single F39L mutation had lower blood phenylalanine concentrations at diagnosis than those with two null mutations $(p=0.003)$ (fig $2)$. In the English series there was a corresponding difference in that children with the single L48S mutation had lower values than the children with both null mutations $(p=$ 0.048 ). There was a suggestion that the English children with the single L48S gene had lower values than the Scottish children with F39L, but the difference did not achieve statistical significance $(p=0.095)$.

\section{Discussion}

In the family reported here, four mutations in different combinations have given rise to hyperphenylalaninaemia. Three of these (L48S, F39L, and R111X) have been found in the PKU populations in other parts of the world including Germany, ${ }^{13}$ Turkey, ${ }^{13}$ Italy, ${ }^{14}$ Sicily, ${ }^{15}$ Australia, ${ }^{16}$ and the Orient. ${ }^{1718}$ The fourth, S67P, has not been reported previously and appears to be a private mutation. In the south west of England F39L is relatively rare whereas L48S is the fourth most common mutation, after IVS12nt1g $\rightarrow \mathrm{a}, \mathrm{R} 408 \mathrm{~W}$, and $\mathrm{I} 65 \mathrm{~T} .{ }^{19}$ In

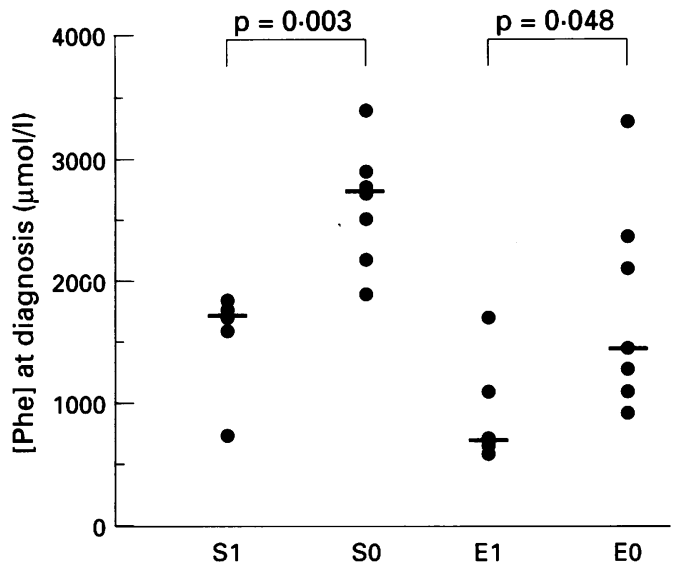

Figure 2 Phenylalanine concentrations in subjects carrying F39L or L48S mutations. Cross bars represent the median value. S1: Scottish patients carrying F39L/ null mutations. So: Scottish patients carrying two null mutations. E1: English patients carrying L48S/null mutations. E0: English patients carrying two null mutations.

western Scotland, on the other hand, the relative frequencies are virtually reversed where L48S is rare and F39L, along with IVS12nt $1 \mathrm{~g} \rightarrow \mathrm{a}$, is the third most common after R408W and I65T. ${ }^{19}$ This pattern parallels that which is observed for the exon 12 mutations (R408W and IVS12) ${ }^{19}$ and is further evidence of the different ancestries of the two populations. R111X has not been found on any other mutant chromosome in this study. It was previously reported in the PKU populations of the Orient ${ }^{1718}$ on haplotype 4 . In this family it is on a haplotype 5 which bears little similarity to haplotype 4 using eight RFLP markers. ${ }^{20}$ Since a CpG dinucleotide is involved ${ }^{21}$ the mutation could have arisen independently on these two haplotype backgrounds.

Direct evidence of the quantitative effects on $\mathrm{PAH}$ activity in in vitro expression systems is not available for the mutations found in this family. However, a non-parametric statistical comparison of the blood phenylalanine concentration at diagnosis in subjects who carry L48S and F39L in combination with known null mutations suggests that both are less deleterious than null mutations. The results on L48S are compatible with those of Konecki et $a l^{13}$ who have reported that patients homozygous for L48S manifested a less severe phenotype and were classified as having mild PKU.

In this family the diverse biochemical presentations in affected subjects can be explained, in part, by their different combinations of mutations. The most severe hyperphenylalaninaemia which has required dietary phenylalanine restriction since infancy is seen in III 1 who has L48S in combination with R111X, a mutation which creates a premature stop codon. Although we have not been able to establish the relative quantitative effect of the private mutation, S67P, the child's phenylalanine concentration at diagnosis and virtual absence of dietary phenylalanine restriction make it almost certain that this is also a less deleterious one. 
The older men appear to have two milder mutations, and despite having moderately raised blood phenylalanine concentrations they showed no overt sign of impaired intellectual development or neurophysiological dysfunction. However, detailed psychological assessment was not undertaken, and so it is possible that there has been some mild impairment of specific areas of cognitive function. Nevertheless, I 1 held desk jobs requiring arithmetical skills during his working life.

It has been recognised for some time that not all people with untreated PKU will suffer mental handicap..$^{22}$ Equally, mutation analysis at the PAH gene now shows that not all subjects with the same genotype will have the same biochemical phenotype, a variability which can be seen both within and between families. ${ }^{7}$ The precise biological mechanisms by which phenotypic variation occurs are not known but it is certain that the contributing factors are multiple and varied. Treacey et $a l^{23}$ for example, have shown that whereas there is identical hydroxylation of phenylalanine to tyrosine in affected sibs with the same genotype, there can be variation in phenylalanine use through additional pathways involved in phenylalanine homeostasis. Ramus et $\mathrm{al}^{7}$ invoke the possibility of a gene which modifies the effect of high phenylalanine concentrations on the brain.

Thus, it is clear that for the disorders of metabolism in vitro expression systems are useful laboratory tools for establishing the more proximate effects of a particular mutation, such as the effects on mRNA synthesis, protein synthesis, or enzyme activity. This allows a relative order of severity of various mutations to be established. However, the more ultimate effects in affected subjects (ease of dietary biochemical control or clinical outcome in treated or untreated patients) must take into account additional complementary influences that are involved both in phenylalanine metabolism in particular and in intellectual and neurophysiological development in general. Ultimately, a simple correlation may not always be apparent between genotype at the PAH gene and biochemical and clinical phenotype.

This work has been supported by grants from the Wellcome Trust (AS), the Deutsche Forschungsgemeinschaft (JZ), and the Research Trust for Metabolic Diseases in Children (AH). In addition, we are grateful to the Showering Trust, Southmead In addition, we are grateful to the Showering Trust, Southmead Hospital, the National Society for Phenylketonuria, and the port. We wish to thank Dr Per Guldberg, Denmark, for inport. We wish to thank Dr Per Guldberg,
structions in the DGGE mutation analysis.
1 Scriver CR, Byck S, Prevost L. PAH mutation analysis consortium newsletter. Montreal, Quebec: October 1994.

2 Lyonnet S, Caillaud C, Rey F, et al. Molecular genetics of phenylketonuria in Mediterranean countries: a mutation associated with partial phenylalanine hydroxylase deficiency. Am ₹ Hum Genet 1989;44:511-17.

3 John SWM, Scriver CR, Laframboise R, Rozen R. In vitro and in vivo correlations for $\mathrm{I} 65 \mathrm{~T}$ and $\mathrm{MIV}$ mutations at the phenylalanine hydroxylase locus. Hum Mutat 1992;1: 147-53.

4 Okano Y, Eisensmith RC, Guttler F, et al. Molecular basis of phenotypic heterogeneity in phenylketonuria. $N$ Engl $\mathcal{F}$ Med 1991;324:1232-8.

5 Svensson D, Eisensmith RC, Dworniczak B, et al. Two missense mutations causing mild hyperphenylalaninaemia associated with DNA haplotype 12. Hum Mutat 1992;1: 129-37.

6 Okano Y, Eisensmith RC, Dasovich M, Wang T, Guttler F, Woo SLC. A prevalent missense mutation in Northern Europe associated with hyperphenylalaninaemia. Eur $f$ Pediatr 1991;150:347-52.

7 Ramus S, Forrest SM, Pitt DB, Saleeba JA, Cotton RGH. Comparison of genotype and intellectual phenotype in untreated PKU patients. F Med Genet 1993;30:401-5.

8 Tyfield LA, Meredith AL, Osborn MJ, et al. Genetic analysis of treated and untreated phenylketonuria in one family. $\mathcal{F}$ Med Genet 1990;27:564-8.

9 Tyfield LA, Stephenson A, Bidwell JL, et al. Mutation analysis of the phenylalanine hydroxylase gene using heteroduplex analysis with synthetic DNA constructs. Acta Paediatr Scand Suppl 1994;83:47-9.

10 Wood NAP, Tyfield LA, Bidwell JL. Rapid classification of phenylketonuria genotypes by analysis of heteroduplexes generated by PCR-amplifiable synthetic DNA. Hum Mutat 1993;2:131-7.

11 Guldberg P, Henriksen KF, Guttler F. Molecular analysis of phenylketonuria in Denmark: $99 \%$ of the mutations detected by denaturing gradient gel electrophoresis. Gendetected by denaturing
omics 1993;17:141-6.

12 Zschocke J, Graham CA, Stewart FJ, Carson DJ, Nevin NG. Automatic sequencing detects all mutations in Northern Irish patients with phenylketonuria and mild hyperphenylalaninaemia. Acta Paediatr Scand Suppl 1994; 83:37-9.

13 Konecki DS, Schlotter M, Trefz FK, Lichter-Konecki U. The identification of two missense mutations at the PAH gene locus in a Turkish patient with phenylketonuria. Hum Genet 1991;87:389-93.

14 Dianzani I, Giannattasio S, deSanctis L, et al. Genetic history of phenylketonuria mutations in Italy. Am $\mathcal{F}$ Hum Genet 1994;55:851-3.

15 Guldberg P, Romano V, Ceratto N, et al. Mutation spectrum of phenylalanine hydroxylase deficiency in Sicily: implications for diagnosis of hyperphenylalaninaemia in Southern Europe. Hum Molec Genet 1993;2:1703-7.

16 Forrest SM, Dahl HH, Howells DW, Dianzani I, Cotton RGH. Mutation detection in phenylketonuria by using chemical cleavage of mismatch: importance of using probes from both normal and patient samples. Am f Hum probes from both normal $1991 ; 49: 175-83$.

17 Huang SZ, Zhou XD, Ren ZR, Zeng YT, Woo SLC. Prenatal detection of an arg ter mutation at codon 111 of the PAH gene using DNA amplification. Prenat Diagn 1990;10:289-93.

18 Takarada Y, Yamashita K, Ohtsuka N, Kagawa S, Matsuoka A. Novel homozygous mutation of phenylalanine hydroxylase gene in a Chinese patient with phenylketonuria Clin Chem 1993;39:1350.

19 Tyfield LA, Bidwell JL, Wood NAP, Cockburn F, Harvie A. PKU in Britain - identification of regional differences in mutations and their historical significance. 2nd International Workshop on Phenylketonuria, Troina, Italy 11-13 November 1993, PG10 (Abstract).

20 Woo SLC. Molecular basis and population genetics of phenylketonuria. Biochemistry 1989;28:1-7.

21 Cooper DN, Youssoufian H. The CpG dinucleotide and human genetic disease. Hum Genet 1988;37:629-34.

22 Pitt D. Phenylketonuria with normal intelligence: report of two cases. Aust $\mathcal{7}$ Ment Res 1971;1:160-3.

23 Treacy E, Pitt J, Seller K, Thompson G, Ramus S, Cotton R

Phenylalanine metabolism in vivo in mild phenylketonuria, the effect of multiple loci. Am ₹ Hum Genet Suppl 1994; the effect
55:A262. 